\title{
Post renal-transplant malignancy surveillance
}

\author{
Authors: Revathy Manickavasagar ${ }^{A}$ and Raj Thuraisingham ${ }^{B}$
}

\begin{abstract}
It is well recognised that kidney transplant recipients have an increased risk of cancers compared with the age and gender matched general population. Malignancy is one of the commonest causes of death among this cohort after cardiovascular disease. This increased risk is largely attributable to the effect of immunosuppression, which impairs T cell function, immunosurveillance and the immunological control of oncogenic viral infections. Cancer related mortality rates are also higher in solid organ transplant recipients compared with the general population. While early diagnosis may improve outcomes in these patients, cancer screening is debatable given the lack of randomised controlled trials in this cohort, and treatment is often challenging. This article reviews the epidemiology and risk factors for the development of malignancy in the post-transplant setting, as well as screening guidelines for specific malignancies of which patients are at particular risk.
\end{abstract}

DOI: 10.7861/clinmed.2019-0423

\section{Introduction}

It is well recognised that kidney transplant recipients have an increased risk of cancers compared with the age and gender matched general population. ${ }^{1-3}$ Malignancy is the leading cause of death among this cohort in the UK, followed by cardiovascular disease and infection. ${ }^{4-7}$ The increased risk of malignancy is largely attributable to the effect of immunosuppression, which impairs $T$ cell function, immunosurveillance and the immunological control of oncogenic viral infections..$^{6,8,9}$ Cancer related mortality rates are also higher in solid organ transplant recipients compared with the general population. ${ }^{10}$ While there are clear cancer screening programmes for the general population in the UK, it is unclear how to optimally screen transplant recipients in terms of specific cancers and the frequency and modality of screening test., ${ }^{1,11}$ Early diagnosis may improve outcomes in the transplant recipient, but treatment is often challenging. ${ }^{1,5,8,9}$

\section{Epidemiology}

Large population cohort studies consistently demonstrate a two to four-fold increased risk of cancer in kidney transplant recipients

Authors: A specialist registrar in nephrology, Royal London Hospital, London, UK; ${ }^{B}$ consultant nephrologist, Royal London Hospital, London, UK compared with the age and gender matched general population, particularly for virus related cancers. ${ }^{6,8,9}$ The increased risk of malignancy is type specific, with the greatest risk being for Kaposi's sarcoma (80-500 times more frequent), non-melanocytic and melanocytic skin cancers, non-Hodgkin lymphoma, colorectal cancer, renal cell cancer and cancers of the anogenital tract. ${ }^{9}$ There is a moderately increased risk of lung cancer and multiple myeloma, but no increase in breast, ovarian, prostate and brain cancers (Table 1). 6,12,13 The peak incidence is $3-5$ years post transplant, however this varies with the age of the recipient and type of cancer. ${ }^{5,9}$ The prognosis of kidney transplant recipients who develop recurrent or de novo cancer is relatively poor compared with the general population. ${ }^{8}$ Treatment is challenging in this cohort, as optimal management with intensive chemotherapy and surgery may be limited by comorbidities such as cardiovascular disease, and a hesitancy to reduce immunosuppression given the risk of graft rejection and loss. ${ }^{1,11}$

\section{Pathogenesis and risk factors}

Recipient, donor and immunosuppression related risk factors contribute to the development of malignancies in the post-transplant

\section{Key points}

Malignancy risk is increased by two to four-fold in transplant recipients compared with the age and gender matched general population.

Cancer related mortality rates are higher in solid organ transplant recipients compared with the general population, and treatment is often challenging.

The increased risk in malignancy is largely attributable to the effects of immunosuppression.

Significant oncogenic viruses in the transplanted individual include Epstein-Barr virus, human herpes virus 8, human papilloma virus, Merkel cell polyomavirus, hepatitis B and hepatitis $\mathrm{C}$.

Screening in the post-transplant patient is recommended by most international clinical guidelines for skin, cervical and colorectal cancer.

KEYWORDS: Transplant, malignancy, malignancy screening, oncogenic viruses, nephrology 
Table 1. The standard incidence ratio of cancers following kidney transplantation ${ }^{13}$

$\begin{array}{ll}\begin{array}{ll}\text { Standard incidence } \\ \text { ratio }^{a}\end{array} & \text { Common cancers following kidney } \\ \text { transplant } \\ >5 & \text { Kaposi's sarcoma } \\ & \text { NMSC } \\ & \text { PTLD / non-Hodgkin } \\ & \text { lymphoma } \\ & \text { Kidney } \\ & \text { Vulvular } \\ & \text { Penile } \\ & \text { Anogenital } \\ & \text { Liver } \\ & \text { Lip } \\ & \text { Cervical } \\ & \text { Thyroid } \\ & \text { Melanoma } \\ & \text { Oesophageal } \\ & \text { Multiple myeloma } \\ & \text { Leukaemia } \\ & \text { Oropharyngeal } \\ & \text { Bladder } \\ & \text { Colon } \\ & \text { Breast } \\ & \text { Ovarian } \\ & \text { Uterine } \\ & \text { Pancreatic } \\ & \text { Brain } \\ & \text { Prostate } \\ & \text { Testicular } \\ & \text { Lung } \\ & \\ & \\ & \\ & \\ & \end{array}$

$\mathrm{a}=$ the standard incidence ratio reflects the fold-increased risk of a malignancy in the kidney transplant recipient compared with the general population; NMSC = non-melanomatous skin cancers; PTLD = post-transplant lymphoproliferative disorder.

setting. ${ }^{6}$ Recipient related risk factors include age, sun exposure, previous cancer and concomitant viral infections. ${ }^{6,14}$ While donortransmitted malignancies have occurred, this is a rare event. ${ }^{6,14}$

Immunosuppression is considered the most important risk factor for post-transplant cancer development via multiple mechanisms, including decreased immune surveillance of cancers, decreased antiviral response facilitating unchecked replication of oncogenic viruses, interference with normal deoxyribonucleic acid repair mechanisms, and possibly direct carcinogenic effect of immunosuppressive agents such as ciclosporin and azathioprine. 5,6,8,11

Viral infections (reactivation of latent infection or primary infection) are implicated in several cancers in both the general population and the immunosuppressed. Viruses associated with carcinogenesis in the post-transplant setting include Epstein-Barr virus (EBV), human herpes virus 8 (HHV-8), human papillomavirus (HPV), Merkel cell polyomavirus, hepatitis B and hepatitis C (Table 2). ${ }^{6,9}$

\section{Screening}

Given the increased cancer incidence and poorer prognosis, prevention and screening may play an important role in reducing
Table 2. Malignancies associated with viral infections ${ }^{6,11,13}$

$\begin{array}{ll}\text { Virus } & \text { Associated Cancer } \\ \text { EBV } & \text { PTLD } \\ \text { HPV-16 and 18 } & \text { Cervical } \\ & \text { Vulval } \\ & \text { Vaginal } \\ & \text { Anal } \\ & \text { Head and neck cancers } \\ & \text { Kaposi's sarcoma } \\ \text { HHV-8 } & \text { Multicentric Castleman disease } \\ & \text { Primary effusion lymphoma } \\ & \text { Multiple myeloma } \\ & \text { Hepatocellular carcinoma } \\ \text { HBV and HCV } & \text { Merkel cell carcinoma } \\ \text { HIV } & \text { HBV = hepatitis B virus; HCV = hepatitis C virus; HHV = human herpes virus; } \\ \text { HPV = human papilloma virus; PTLD }=\text { post-transplant lymphoproliferative } \\ \text { disorder. }\end{array}$

the burden of cancer in kidney transplant recipients. ${ }^{9}$ However, Wong et al's critical evaluation of cancer screening guidelines highlighted that current recommendations are extrapolated from study findings in the general population. ${ }^{1}$ To date, there is little evidence that enhanced screening is of value apart from in selected conditions such as skin, cervical, colorectal and native kidney cancers. ${ }^{15-17}$ In spite of this, there is no consensus among existing international guidelines regarding the value of screening, optimal modality and frequency for these conditions. We discuss below the current UK guidelines from the Renal Association (RA) which have been endorsed by the British Transplant Society (BTS), and the NHS cancer screening programme.

\section{Skin cancer}

Non-melanomatous skin cancers (NMSC) are the most common malignancy in the transplanted patient, with squamous and basal cell carcinomas accounting for over $90 \%$ of all skin cancers. ${ }^{6}$ In addition, transplantation greatly enhances the incidence of Kaposi's sarcoma for those at risk. ${ }^{2}$ The RA recommends that kidney transplant recipients are educated about the adverse effects of solar exposure and have an individualised assessment based on their unique risk factors. ${ }^{15}$ General measures of prevention (use of sunscreen, hats, avoidance of exposure to ultraviolet radiation during sun peak hours) should be employed by all patients and perhaps should also be practiced by patients with chronic kidney disease in anticipation of possible heightened risk in the future. ${ }^{9,15}$ Post transplantation, self-examination of the skin is encouraged, and should be supplemented by at least biannual review by a trained healthcare professional up to 5 years post transplant, and annual review from 5 years. ${ }^{15}$ A more tailored surveillance programme is recommended by some specialist dermatologists based on risk stratifying patients according to skin type and other risk factors including ethnicity. ${ }^{5}$

In those who have had $\geq 2$ previous NMSCs, acitretin $(0.2-$ $0.4 \mathrm{mg} / \mathrm{kg} /$ day) may reduce NMSCs, hence should be considered in those with previous skin cancer. ${ }^{15,18}$ In addition, changing immunosuppression to a mammalian target of rapamycin 
inhibitor (mTORi) based treatment may decrease the risk of incident second tumours, however this may be at the expense of side effects and adverse effects on graft function. $6,15,19$

\section{Cervical cancer}

The incidence of cervical cancer in kidney transplant recipients is two to three times greater than the age and gender matched population, which is thought to be related to pre-cancerous lesions progressing more rapidly under the influence of immunosuppression. ${ }^{6}$ Nevertheless, there is a paucity of evidence to support more frequent screening in the transplant cohort, hence screening should be in accordance with UK guidelines. ${ }^{15}$ For the general population, Papanicolaou cytological screening (Pap smear) is recommended every 3 years between the ages of 2549 years old, and every 5 years for those $50-64$ years old. ${ }^{15,20}$ More frequent monitoring, or continued screening beyond the age of 65 is recommended in those with a history of abnormal smears. ${ }^{15,20}$ There are variations in international guidelines, with the American Society of Transplantation (AST) recommending annual pelvic exams and Pap smears. ${ }^{17}$ While the bivalent and quadrivalent HPV vaccines have been shown to reduce the incidence of HPV-16 and 18 related cervical dysplasia in the general population, its immunogenicity and benefits are yet to be demonstrated in the transplant cohort. ${ }^{15,21}$ Nevertheless, as the HPV vaccination is an inactivated vaccine, it can safely be administered before or after transplantation. ${ }^{15,21}$

\section{Colorectal cancer}

While there is increased risk of colorectal cancer (CRC) by two to three-fold among those with kidney transplants, there is significant variability in screening guidelines. The RA recommends screening renal transplant recipients similarly to the general population, with 2-yearly faecal occult blood test (FOBT) for men and women aged $60-74$ years ( $50-74$ years in Scotland). ${ }^{15,20}$ In addition, those over 55 years may be invited for a one-off screening colonoscopy if locally available. ${ }^{20}$ Again, recommendations vary in terms of frequency and modality in other international guidelines. ${ }^{17}$

\section{Renal cell cancer}

The incidence of renal cell cancer (RCC) is increased in the native kidneys of renal transplant recipients, particularly those who are at high risk (history of analgesic nephropathy, acquired cystic disease of kidneys, long dialysis vintage, family history of RCC).,11 However, screening has not been demonstrated to be effective in transplant recipients. ${ }^{11,15}$ Screening with ultrasonography is operator dependent and influenced by patient habitus and characteristics of the kidney and tumour. ${ }^{22}$ Additionally, it is insensitive in detecting small lesions, therefore it is not ideal for detecting early-stage disease, and it remains unclear how frequently ultrasound should be performed. ${ }^{19}$ Given these limitations, the RA does not recommend routine screening for RCC in transplant recipients. ${ }^{15}$

\section{Post-transplant lymphoproliferative disorder}

Post-transplant lymphoproliferative disorder (PTLD) is a serious complication of solid organ transplantation, with manifestations varying from uncomplicated infectious mononucleosis to haematological malignancies. ${ }^{23} \mathrm{EBV}$ is recognised to play a key role in the pathogenesis of PTLD. ${ }^{11,13,23,24}$

The RA recommends that both donor and recipient EBV serology should be noted at the time of transplantation, and all high-risk recipients (donor positive / recipient negative) should have EBV viral load measured immediately after transplantation, monthly for 6 months, and 3 monthly for 1 year. ${ }^{15}$ Thereafter, EBV viral load should be monitored after the treatment of rejection, and overall immunosuppression should be reduced when EBV titres rise significantly. ${ }^{15}$ These recommendations assist in identifying patients at risk of developing PTLD, however there are no specific guidelines for screening for the disease in the UK. ${ }^{15}$

\section{Other malignancies}

Recipients with a known history of cirrhosis are recommended to undergo annual hepatic ultrasound and alpha-fetoprotein levels for screening for hepatocellular cancer, in keeping with the NHS guidelines for the general population. ${ }^{15,20}$ Transplant recipients are not recognised to be at increased risk of breast cancer and thus should be screened in accordance with national guidelines. ${ }^{20}$ This includes self-examination and, for women aged $50-71$ years, mammography every 3 years. ${ }^{15,20}$ Self-examination is also recommended by the RA for testicular cancer. ${ }^{15}$ At present there is no prostate cancer screening programme in the UK, and there is no additional screening recommended for transplant recipients. ${ }^{15,20}$

\section{Summary}

Malignancy is a leading cause of morbidity and mortality in renal transplant recipients and management involves a multidisciplinary approach. Cancer surveillance, early detection and treatment may improve outcomes in these patients; however, there is little agreement in how this should be carried out. Nevertheless, there is consensus that transplant recipients should be aware of their increased malignancy risk and encouraged to report symptoms which may signify de novo malignancy. ${ }^{15-17}$ In addition, patients should have an individualised screening plan taking into account their risk factors and the value of available screening tools.

\section{References}

1 Wong G, Chapman JR, Craig JC. Cancer screening in renal transplant recipients: What Is the evidence? CJASN 2008;3(Suppl 2):S87-100.

2 Kasiske BL, Snyder J], Gilbertson DT, Wang C. Cancer after kidney transplantation in the United States. Am J Transplant 2004;4:905-13.

3 Vajdic CM, McDonald SP, McCredie MR et al. Cancer incidence before and after kidney transplantation. JAMA 2006;296:2823-31.

4 The Renal Association. UK Renal Registry: 21st annual report. Bristol; The Renal Association, 2019.

5 Acuna SA, Huang JW, Scott AL et al. Cancer screening recommendations for solid organ transplant recipients: A systematic review of clinical practice guidelines. Am J Transplant 2017;17:103-14.

6 Sprangers B, Nair V, Launay-Vacher V, Riella LV, Jhaveri KD. Risk factors associated with post-kidney transplant malignancies: an article from the Cancer-Kidney International Network. Clin Kidney ] 2018;11:315-29.

7 Briggs JD. Causes of death after renal transplantation. Nephrology Dialysis Transplantation 2001;16:1545-9.

8 Lim WH, Au E, Krishnan A, Wong G. Assessment of kidney transplant suitability for patients with prior cancers: is it time for a rethink? Transpl Int 2019;32:1223-40. 
9 Chapman JR, Webster AC, Wong G. Cancer in the transplant recipient. Cold Spring Harb Perspect Med 2013;3:a015677.

10 Kiberd BA, Rose C, Gill JS. Cancer mortality in kidney transplantation. Am J Transplant 2009;9:1868-75.

11 Au E, Wong G, Chapman JR. Cancer in kidney transplant recipients. Nat Rev Nephrol 2018;14:508-20.

12 Tessari G, Naldi L, Boschiero L et al. Incidence of primary and second cancers in renal transplant recipients: a multicenter cohort study. Am J Transplant 2013;13:214-21.

13 Morath C, Mueller M, Goldschmidt $\mathrm{H}$ et al. Malignancy in renal transplantation. JASN 2004;15:1582-8.

14 Baker RJ. Renal Association clinical practice guideline postoperative care in the kidney transplant recipient. BMC Nephrol 2017;18;174.

15 EBPG Expert Group on Renal Transplantation. European best practice guidelines for renal transplantation. Section IV: Long-term management of the transplant recipient. Nephrol Dial Transplant 2002;17(Suppl 4):1-67.

16 American Society of Transplantation. Guidelines for post-kidney transplant management in the community setting. AST, 2009. www.myast.org/guidelines-post-kidney-transplant-managementcommunity-setting- 0 .

17 Kadakia KC, Barton DL, Loprinzi CL et al. Randomized controlled trial of acitretin versus placebo in patients at high-risk for basal cell or squamous cell carcinoma of the skin (North Central Cancer Treatment Group Study 969251). Cancer 2012;118:2128-37.

18 Salgo R, Gossmann J, Schofer $\mathrm{H}$ et al. Switch to a sirolimus-based immunosuppression in long-term renal transplant recipients: reduced rate of (pre-)malignancies and nonmelanoma skin cancer in a prospective, randomized, assessor-blinded, controlled clinical trial. Am J Transplant 2010;10:1385-93.

19 NHS. NHS screening. NHS, 2018. www.nhs.uk/conditions/nhsscreening

20 Kumar D, Unger ER, Panicker G et al. Immunogenicity of quadrivalent human papillomavirus vaccine in organ transplant recipients. Am J Transplant 2013;13:2411-7.

21 Rossi SH, Klatte T, Usher-Smith J, Stewart GD. Epidemiology and screening for renal cancer. World J Urol 2018;36:1341-53.

22 Allen UD, Preiksaitis JK. Epstein-Barr virus and posttransplant lymphoproliferative disorder in solid organ transplantation. Am J Transplant 2013;13(Suppl 4):107-20.

23 Kidney Disease: Improving Global Outcomes (KDIGO) Transplant Work Group. KDIGO clinical practice guideline for the care of kidney transplant recipients. Am J Transplant 2009;9(Suppl 3):S1155.

24 Asch WS, Bia MJ. Oncologic issues and kidney transplantation: a review of frequency, mortality, and screening. Adv Chronic Kidney Dis 2014;21:106-13.

Address for correspondence: Dr Raj Thuraisingham, Royal London Hospital, Whitechapel Road, Whitechapel, London E1 1BB, UK.

Email: raj.thuraisingham@nhs.net

\section{Consent and confidentiality in genomic medicine}

\section{Genetic or genomic tests are increasingly used in everyday medical practice. Every clinical field will encounter such tests to a greater or lesser extent.}

\begin{abstract}
Published in 2019, this third edition by the Joint Committee on Genomics in Medicine provides updated guidance on the use of genetic and genomic information in the clinic. Health professionals from all areas of medicine need to know and understand how consent and confidentiality issues may arise, and to understand the potential ways in which the use of genomic tests may change the nature of the relationship between healthcare professionals and patients.
\end{abstract}

Download the guidance at: www.rcplondon.ac.uk/consent-confidentiality-genomic-medicine

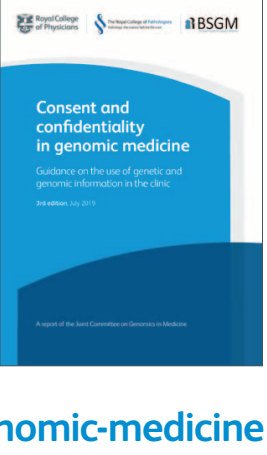

